\title{
Constituição e funcionamento do Conselho Municipal de Educação frente ao processo de democratização da gestão: um estudo dos municípios de Santa Maria e Santa Rosa/RS
}

Sueli Menezes Pereira*

Oséias Santos de Oliveira**

\section{Resumo}

0 artigo parte de um estudo qualitativo, calcado em uma pesquisa bibliográfica e documental com objetivo de discutir aspectos referentes à constituição e funcionamento do Conselho Municipal de Educação (CME), como órgão colegiado que se reveste de importante significado para a democratização da gestão educacional. A ênfase da análise recai sobre os CMEs dos municípios gaúchos de Santa Maria e Santa Rosa que, dadas as suas diferenças e peculiaridades, projetam tais órgãos ainda atrelados a uma estrutura formal intermediária. 0 desafio dos CMEs é funcionar de forma autônoma frente as suas inúmeras atribuições de modo a dar respostas que sinalizem à criação de novos caminhos à educação pública municipal. Atuar de forma diferenciada em um cenário onde a maioria dos conselhos se alinham a uma lógica formal e burocratizada e onde ainda são vistos como órgão de assessoramento do poder governamental é, sem dúvida, uma meta a ser perseguida na busca da democratização deste espaço público.

Palavras-chave: Conselhos Municipais de Educação. Democratização. Autonomia. Representação social.

\footnotetext{
* Doutora em Educação; Professora do Programa de Pós-Graduação em Educação, Universidade Federal de Santa Maria (UFSM), RS; Professora lotada no Departamento de Administração Escolar do Centro de Educação, UFSM/RS. E-mail: sueli@ce.ufsm.br

** Doutorando em Educação, Programa de Pós-Graduação em Educação, UFSM/RS; Integrante do Grupo de Pesquisa em Políticas Públicas e Gestão Educacional. E-mail: oseiasol@yahoo.com.br
} 


\section{Constitution and operation of the Municipal} Council of Education before regarding the process of democratizing management: a study about the municipalities of Santa Maria and Santa Rosa

\section{Abstract}

The article departs from a qualitative study grounded upon bibliographic and documentary research and aims to discuss certain aspects concerning the constitution and operation of the Municipal Council of Education (CME), as a collegiate invested with important meaning for the democratizatizing management of education. The emphasis of the analysis falls on the CMEs 'gaucho' municipalities of Santa Maria and Santa Rosa taking into consideration their differences and peculiarities both, notwithstanding, designed as formal intermediary or subordinate structures. The challenge to the CMEs is to operate autonomously before their countless assignments, in order to give responses which signal the opening of new paths to the municipal public education. Acting through this different way in a context where most of the councils are aligned with a formal and bureaucratized logic, and where they are still thought of as advisory organs of the ruling power is, undoubtedly, a goal to be pursued in the general effort to democratize this public space.

Keywords: Municipal Councils of Education. Democratization. Autonomy. Social representation.

\section{Constituición y funcionamiento del Consejo} Municipal de Educación frente al proceso de democratización de la gestión: un estudio de los municipios de Santa Maria y Santa Rosa/RS Resumem

El artículo parte de un estudio cualitativo, basado en una investigación bibliográfica y documental con el objeto de discutir aspectos referentes a la constitución y al funcionamiento del Consejo Municipal de Educación (CME), como órgano colegiado que tiene importante significado para la democratización de la gestión educacional. El énfasis del análisis se concentra en los CMEs (Consejos Municipales de Educación) de los municipios de Santa María y Santa Rosa del Estado de Rio Grande do Sul, Brasil, que, en razón de sus diferencias y peculiaridades proyectan los referidos órganos todavía arraigados a una estructura formal intermediaria. El desafio de los CMEs es poder funcionar de forma autónoma frente a sus innumerables 
atribuciones para dar respuestas que orienten la creación de nuevos caminos hacia la educación pública municipal. Actuar de manera distinta en un escenario en que la mayoría de los consejos se encuadran en una lógica formal y burocratizada y donde todavía se los ve como órganos de asesoramiento del poder gubernamental es, sin duda, una meta que debe querer alcanzarse en la búsqueda de la democratización de este espacio público.

Palabras-clave: Consejos Municipales de Educación. Democratización. Autonomía. Representación social.

\section{Introdução}

A descentralização político-administrativa do Estado neoliberal se traduz na gestão democrática efetiva do Sistema de Ensino e, neste contexto, situa-se o Conselho Municipal de Educação (CME) por se constituir órgão de representatividade social e deliberação coletiva, devendo ocupar espaço de destaque na normatização da política municipal de educação, bem como na elaboração do Plano Municipal de Educação (PME). Isto ocorre porque, sendo "órgãos colegiados de caráter normativo, deliberativo e consultivo que interpretam e resolvem, segundo suas competências e atribuições a aplicação da legislação educacional" (CURY, 2000, p. 44), os Conselhos Municipais de Educação têm a função de intermediação entre o Estado e a sociedade, devendo ter uma ampla representação da sociedade civil no trato das políticas públicas.

A representação social é percebida na constituição dos conselhos como a abertura de lócus públicos de participação, o que, potencialmente, favorece a consolidação de um processo de municipalização assentado em bases democráticas de gestão pela qual, os espaços, até então dominados por organizações hierárquicas e burocráticas, possibilitam o exercício participativo, mesmo que indireto, por ser esta a condição possivel no capitalismo.

Sob o viés da democracia no capitalismo, Gadotti (2000, p. 169) posiciona-se, em contraponto, revelando que, quando a comunidade estiver realmente representada no CME e isto se configurar com resultados diretos para a organização da educação municipal:

O CME permite a participação da sociedade na fixação dos rumos da educação através do exercício da democracia direta. A fixação de prioridades e metas em conjunto com as representações dos vários segmentos sociais permite ao executivo identificar e suprir, com maior precisão e eficácia, as necessidades existentes.

Destaca-se com o autor (GADOTI, 2000) que os Conselhos Municipais de Educação não são instâncias recém-concebidas ou implantadas, resultantes do processo de 
descentralização de poder do Estado na organização da educação contemporânea, embora passem a se portar como espaços fundamentais para que os Sistemas Municipais de Educação (SME) se consolidem. Isto fica evidente quando se analisam os muitos estudos relacionados ao tema, demonstrando que a problemática da educação municipal no Brasil é pauta de discussões desde a época imperial e vem se fazendo presente nos debates políticos relacionados à descentralização do ensino.

De acordo com Teles (2001, p. 2), desde o Império

[...] já havia a proposição de constituir conselhos de educação como órgãos da administração educacional. Há registros de conselhos centrais, pertencentes ao governo central da província ou do Império; conselhos mais locais, que recebiam variadas denominações, como por exemplo, conselhos paroquial, distrital, ou conselhos literários. Isto permite inferir, que desde o início da organização dos nossos sistemas educacionais, já se pensava em órgãos colegiados como parte da administração do setor.

A estruturação de sistemas públicos, no entanto, se firma com as Constituições Federais (BRASIL, 1934, 1946), das quais resultou a criação de Sistemas de Educação, também, em âmbito estadual, além do federal. Somente com a Carta Constitucional de 1988 (BRASIL, 1988) resulta a criação de Sistema na esfera municipal para o que contribui decisivamente a Lei de Diretrizes e Bases (LDB) - Lei $n^{\circ} 9.394$ (BRASIL, 1996) - ao definir claramente a competência dos Municípios para a instituição de seus próprios Sistemas de Ensino e, com isto, a consolidação do Conselho Municipal de Educação como órgão imprescindivel deste Sistema.

Frente a isto, o presente trabalho se reporta, inicialmente, à criação, constituição e funções de Conselhos de Educação (CE) na educação brasileira e, na atualidade, o Conselho Municipal de Educação. Através de pesquisa documental, tendo na legislação a fonte primária de análise, busca verificar a constituição e função que assumem os CMEs no processo de descentralização de poder, visando à democratização das decisões na área educacional o que se configura, tanto por sua representação social, quanto por suas atribuições frente à problemática da educação municipal. Para tanto, a pesquisa, do tipo estudo de caso, se vale da realidade de dois municípios do Rio Grande do Sul: Santa Maria e Santa Rosa pertencentes a duas diferentes regiões do Estado Região Central e Região Noroeste, respectivamente. Justifica-se a escolha destes dois municípios por serem os mesmos focos de um projeto de pesquisa que trata da democracia, da autonomia e da qualidade da educação municipal em desenvolvimento no "Grupo de Estudos em Políticas Públicas e Gestão Educacional" (GEPPGE/UFSM). 
Na análise da realidade educacional de Santa Maria e Santa Rosa observa-se a singularidade de cada município na organização de seus respectivos Sistemas de Ensino, o que sinaliza características diferenciadas na constituição e funcionamento de seus devidos CMEs.

\section{Os Conselhos de Educação no Brasil}

Conforme Teixeira (2004, p. 692), o vocábulo conselho, na etimologia greco-latina se refere, para os gregos, à "ação de deliberar", "cuidar", "cogitar", "refletir", "exortar". "Em latim, traz a idéia de "ajuntamento de convocados", o que supõe participação em decisões precedidas de análises, de debates", indicando o seu caráter democrático.

Contrastando com a história da administração da educação, marcada por uma tradição de cunho fortemente centralizador, os Conselhos de Educação assumem importante papel no processo de constituição dos sistemas educacionais brasileiros, devendo, em sua dinâmica política, ultrapassar o setor educacional e se constituírem em órgãos de união entre o Estado e a sociedade de modo a democratizar a política educacional.

A administração por conselhos tem sua origem desde os primórdios da Colônia, passando pelo Império até as diferentes formas de organização da República, assumindo, ora função política e fiscalizadora, ora executora, ora função técnica. "Como órgãos de fiscalização dos estabelecimentos de ensino mantidos pela União" (TEIXEIRA, 2004, p. 694), os Conselhos de Educação tinham a finalidade de garantir as "funções de homogeneização cultural e moralização das populações" que caracterizaram o Império e a República Velha (TELES, 2001, p. 1).

Explica a autora que, naquele momento

[...] surge o discurso da descentralização das decisões políticas, e é criado o Conselho Superior, com desdobramentos nas províncias através dos Conselhos Escolares centrais ou distritais; a descentralização na ação é mais no sentido burocrático e não político, pois os debates entre as elites politicas e intelectuais ainda continuaram fortemente centralizados (TELES, 2001, p. 3).

Na I República foram criados: o Conselho Superior de Instrução Pública e o Conselho Superior de Ensino, ambos com caráter administrativo, voltados para o Ensino Superior e, mais tarde, o Conselho Nacional do Ensino, com função executiva. Com a criação do Ministério de Educação e Saúde Pública em 1931, este ConseIho foi recriado com o nome de Conselho Nacional de Educação (CNE), assumindo função técnica como parte da estrutura burocrática do Estado, tornando-se órgão colaborador do Poder Executivo. Sua principal atribuição foi a elaboração do Plano Nacional de Educação (PNE) (TEIXEIRA, 2004). 
A autora (TEIXEIRA, 2004) observa, ao analisar o Decreto $n^{\circ}$ 19.850/1931 que cria e regulamenta este órgão que, além da função técnica que Ihe é atribuida, também:

[...] se atribuiam funções consultivas, mais que de execução na condução das questões do ensino a cargo da União. Tal feição administrativa se acha ainda reforçada na definição dos critérios de escolha de seus membros (art. $3^{\circ}$ ), que estabelece como exigência que sejam 'pessoas de reconhecida competência para as funções e, de preferência, experimentadas na administração do ensino e conhecedoras das necessidades nacionais' (grifo da autora) (TEIXEIRA, 2004, p. 695).

O PNE como atribuição do CNE se constitui em uma modalidade de modernização da educação brasileira, sendo alvo do processo constituinte de 1934 e de todas as reformas de ensino deste período até a década de 1960. Disto resulta a ampliação da composição do CNE, integrando agora, não só representantes do Poder Executivo, mas, também, de profissionais da educação e da cultura, exigência que se torna necessária, considerando as funções atribuídas a este órgão.

Ocupando lugar de destaque na definição do sistema de ensino, até então inexistente, especialmente na resolução do ordenamento legal, o CNE orienta a organização do ensino e se constitui, naquele momento, como órgão técnico, mantendo, contudo, a função normativa que Ihe era atribuída. A organização do Sistema Nacional de Educação no país, no entanto, só acontece após a Revolução de 1930, quando o Brasil se consolida como República Federativa, entendendo-se

[...] regimes federativos (como) a existência de uma complexa engenharia consociativa entre os diferentes pólos de poder entre os quais a relação poder central e poder dos Estados membros, ou em outros termos, a relação centralização x descentralização (CURY, 2008, não paginado).

A ideia de sistema é apontada, especialmente, com a Constituição Federal (BRASIL, 1934) que propõe, não só a criação de Conselhos Estaduais de Educação aos moldes do Conselho Nacional, momento em há a sinalização para a concepção das diretrizes e bases da educação nacional, o que só vai ser efetivado após a promulgação do texto constitucional de 1946, com a LDB de 1961 - Lei no 4.024 (BRASIL, 1961). Cabe considerar que, a partir desta lei, foram instituídos os sistemas federal e estadual de ensino e, com isto, a criação do Conselho Federal de Educação (CFE) e dos Conselhos Estaduais de Educação (CEE), o que consolida os referidos sistemas como organizações independentes e autônomas, tendo nos Conselhos de Educação seus órgãos normativos.

A nova denominação para Conselho Federal de Educação amplia suas responsabilidades, assumindo também funções deliberativas, conservando, no entanto, seu caráter téc- 
nico e normativo, o que "condicionou a seleção dos 24 membros" para a composição do CFE "assegurando-se a representatividade dos profissionais do ensino nos seus diferentes ramos e modalidades, assim como das várias regiões do pais" (TEIXEIRA, 2004, p. 697).

Colaborando na organização e no funcionamento dos sistemas federal e estaduais de ensino, o CFE mantém intercâmbio com os conselhos estaduais, os quais assumem, também, a função normativa que Ihes foi atribuída.

Nos governos militares que aqui se instauraram a partir se 1964, a função normativa dos conselhos de educação torna-se mais abrangente e, nessa direção, a Lei no 5.692 (BRASIL, 1971) atribui-Ihes a função de regulamentar, em caráter complementar, "a organização dos currículos do ensino de primeiro e segundo graus e à adequação do ensino às peculiaridades locais ou regionais". Isto é o que afirma Teixeira (2004, p. 697, grifo nosso), acrescentando:

Contribuiu, dessa forma, para consolidar ainda mais a característica burocrática do funcionamento dos conselhos de educação, que já vinha marcando a atuação destes ao longo de sua história. Por outro lado, a lei, em seu art. 71, facultou aos municípios em que houvesse condições para tal a possibilidade de constituição de seus próprios conselhos de educação, podendo ser a eles delegadas competências pelos respectivos conselhos estaduais.

Ao facultar aos municípios a possibilidade de constituição de seus próprios conselhos de educação, muitos desses têm a data de criação de seus Conselhos Municipais deste período, mantendo-se, no entanto, submissos aos respectivos Conselhos Estaduais no exercício de competências que Ihes foram por estes delegadas. Naquele momento histórico, os CMEs se organizaram como espaço de discussão das questões educacionais do municipio, fase em que a educação sofreu grandes alterações em sua organização e função, cujos resultados não favoreciam uma educação de qualidade social. Isto se explica pela proposta de educação que, representando o caráter político do modelo de Estado que aqui se implanta em bases neoliberais, favorece o privado sobre o público, o que se manifesta também na organização dos conselhos através da ampliação do setor privado em sua composição, bem como na limitação de sua função a um caráter técnico-normativo.

Com a abertura política na década de 1980 e a garantia da gestão democrática da educação pública como princípio da Constituição Federal (BRASIL, 1988, Art. 206) e a descentralização administrativa do ensino (BRASIL, 1988, Art. 208) se fortalece a ideia de ampla participação da sociedade nos órgãos colegiados voltados à organização da educação. É neste prisma que, ao firmar o Município como ente federativo autônomo, a Magna Carta de 1988, em seu art. 211, estabeleceu que a 
União, os Estados, o Distrito Federal e os Municipios "organizarão em regime de colaboração os seus sistemas de ensino", definindo como competência desses últimos a atuação no ensino fundamental e pré-escolar (BRASIL, 1988, Art. 211, \$2º.

Os dispositivos constitucionais de 1988 só foram regulamentados pela Lei $n^{\circ}$ 9.394 (BRASIL, 1996) que estabelece as Diretrizes de Bases da Educação Nacional. Em seu texto, "não apenas ratifica a organização sistêmica, já praticada, como normatiza a condição de sistemas "autônomos" atribuída aos Municipios pela CF 1988" (SOUZA; VASCONCELOS, 2006. p. 43). Assim, estabelecendo o princípio da autonomia municipal, possibilita ao Município compor, articuladamente, com o Estado (BRASIL, 1996, Art. 11, Parágrafo Único) um Sistema Único de Educação Básica através do Regime de Colaboração, o que responsabiliza a União na garantia desse processo através de suas funções normativa, redistributiva e supletiva aos demais entes federados (BRASIL, 1996, Art. $8^{\circ}, \S 1^{\circ}$ ).

0 artigo 11 da LDB (BRASIL, 1996) explicita as incumbências dos municipios, bem como o artigo 18 expressa a composição dos Sistemas Municipais de Ensino. Com isso, a LDB (BRASIL, 1996), efetivamente, garante a constituição dos SME, devendo a decisão de criar o CME ser exclusiva do municipio e, sendo criado, o mesmo assume papel de destaque em um processo cujas políticas favorecem a municipalização do ensino.

Lembramos que o projeto neoliberal que se instala nos anos de 1980 e 1990 na América Latina, após regimes militares centralizados,

[...] num cenário ainda marcado por seqüelas decorrentes de longos periodos de regime autoritário, nos quais predominaram políticas de desinvestimentos em Educação Básica [...] geradoras, em escala alarmante, de índices educacionais negativos traz reformas de cunho político descentralizado dos serviços públicos [...] sob a justificativa de otimizar seus recursos (SOUZA; FARIA, 2004, p. 926-927).

Com isso se institui uma proposta descentralizadora com forte apelo ao envolvimento direto do poder local nas decisões de caráter social,

[...] como forma de desburocratização do Estado e de abertura a novas formas de gestão da esfera pública; da autonomia gerencial para as unidades escolares e, ainda, da busca de incrementos nos índices de produtividade dos sistemas públicos, marcadamente sob inspiração economicista e neoliberal, [...] (fortalecendo) as diferentes formas que a descentralização da educação veio a assumir [...] em termos da municipalização (SOUZA; FARIA, 2004, p. 927). 
0 extensivo programa de descentralização, sobretudo das políticas sociais, ocorrida nos anos de 1990, década da aprovação da LDB (BRASIL, 1996), reorganiza a estrutura da educação pública através de um modelo de gestão que evoca a participação da comunidade através da criação e constituição de conselhos nos sistemas e nas escolas (BRASIL, 1996, Arts. 14, 18). Neste caso, a descentralização representa um espaço de autonomia que, se, criticamente interpretado no contexto sócio, político e econômico que o determinou, poderá ser ocupado de modo que o poder local seja assegurado por conselhos efetivamente participativos de decisões que beneficiem os interesses sociais. Sendo assim, a educação municipal terá no CME um espaço de real representação da comunidade, o que torna este conselho um órgão significativo da "vontade política da sociedade e não uma mera formalidade legal" (BORDIGNON, [2010?], não paginado).

Podendo nascer da mobilização dos educadores, ou do espírito democrático dos dirigentes municipais, sua criação deve resultar, em qualquer caso da mobilização da comunidade. A participação política da sociedade civil no âmbito da educação local é o tema que emerge como ponto central neste texto.

\section{A democratização do CME: propostas legais do SME de Santa Maria e Santa Rosa}

Reafirmando que a Constituição Federal (BRASIL, 1988) reconhece os municípios como entes federados e, nestes, a possibilidade de existência de Sistemas Municipais de Educação, tendo no Conselho Municipal de Educação seu órgão normativo, lembramos com Bordignon ([2010?]) que não há legislação federal determinando a criação do Conselho Municipal de Educação, devendo a decisão de criá-lo ser do próprio município. Não há, portanto um "modelo" que o defina, devendo cada município, de acordo com a singularidade de sua realidade, especialmente do seu Sistema de Ensino, encontrar a organização mais adequada para o desempenho de suas funções.

Ao definir a estrutura própria de gerenciamento da educação pública municipal,

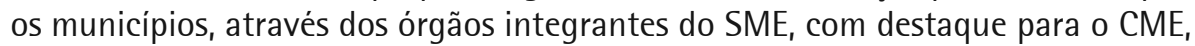
adquirem autonomia para efetivar ações normativas, consultivas e fiscalizadoras das políticas educacionais a serem planejadas e implementadas na própria rede, sem a necessidade de se reportar ao Sistema Estadual de Ensino. Deste modo, localmente organizados, há uma perspectiva de agilização dos processos e normatizações das inúmeras situações gerenciais do próprio sistema.

Nesta ótica, através de atos legais configurados como leis de natureza municipal, se dá a criação dos Sistemas Municipais de Ensino e dos Conselhos Municipais de Educação dos municípios gaúchos de Santa Maria e de Santa Rosa conforme exposto no Quadro 1. 
Quadro 1: Legislação de criação do SME e do CME.

\begin{tabular}{|c|c|}
\hline Santa Maria/RS & Santa Rosa/RS \\
\hline $\begin{array}{l}\text { Lei Municipal } n^{\circ} 4.123 \text { de } 22 / 12 / 1997 \text { - } \\
\text { cria o Sistema Municipal de Ensino de } \\
\text { Santa Maria - SME/SM. }\end{array}$ & $\begin{array}{l}\text { Lei Municipal } n^{\circ} 3.211 \text {, de } 14 / 07 / 1999 \text { - cria o } \\
\text { Sistema Municipal de Ensino de Santa - SME/SR. }\end{array}$ \\
\hline $\begin{array}{l}\text { Lei Municipal n } 4.122 \text { de 22/12/1997 } \\
\text { institui o Conselho Municipal de } \\
\text { Educação de Santa Maria - CME/SM. }\end{array}$ & $\begin{array}{l}\text { Lei Municipal } n^{\circ} 3.212 \text {, de } 14 / 07 / 1999 \text { institui o } \\
\text { Conselho Municipal de Educação de Santa Rosa - } \\
\text { CME/SR. }\end{array}$ \\
\hline
\end{tabular}

Fonte: Santa Maria (1997a, 1997b) e Santa Rosa (2009a, 2009b).

A partir da determinação constitucional, o município de Santa Maria cria seu Sistema Municipal de Educação e seu órgão normativo, o CME, em 22 de dezembro de 1997 por ato do Poder Executivo, pelo qual foram sancionadas as leis municipais $n^{\circ} 4.122$ e $n^{\circ} 4.123$ (SANTA MARIA, 1997a, 1997b), que instituem, respectivamente, o Sistema Municipal de Ensino de Santa Maria (SME/SM) e o Conselho Municipal de Educação de Santa Maria (CME/SM).

No município de Santa Rosa, a criação do Sistema Municipal de Ensino (SME/SR) se dá através da Lei Municipal no 3.211 (SANTA ROSA, 1999a) e o Conselho Municipal de Educação (CME/SR) é criado através da Lei Municipal nº 3.212 (SANTA ROSA, 1999b), ambas datadas de 14 de julho de 1999.

Neste sentido o movimento de criação dos Sistemas Municipais de Ensino, tanto de Santa Maria, quanto de Santa Rosa, insere estes municípios entre os primeiros do Estado do RS no cumprimento dos pressupostos legais, pois conforme aponta Werle, até o ano de 1999 cerca de 40 municipios gaúchos já haviam criado seus sistemas municipais de ensino, o que demonstra que o Estado "tem se mostrado ativo e interessado na constituição de sistemas municipais de educação, desde o final dos anos noventa" (WERLE, 2006, p. 4).

\section{A criação do Sistema Municipal de Ensino: retrospectiva dos municípios de Santa Maria/RS e de Santa Rosa/RS}

Em conformidade com as Diretrizes e Bases da Educação Nacional, expressas na Lei Federal n 9.394, de 20 de dezembro de 1996, são criados os Sistemas Municipais de Educação de Santa Maria e Santa Rosa nos quais se observam semelhanças e diferenças em sua composição e atribuições. 
Em Santa Maria, a Lei no 4.123 (SANTA MARIA, 1997b, Art. 3º) que cria o Sistema Municipal de Ensino, determina que a ele compete "planejar, organizar e implementar políticas educacionais públicas". Esta lei institui o "Regime de Colaboração com os Sistemas de Ensino do Estado e da União" (SANTA MARIA, 1997b, Art. $5^{\circ}$ ); bem como determina a criação de Lei Municipal para regulamentar a "Gestão Democrática nos Estabelecimentos Municipais de Ensino" (SANTA MARIA, 1997b, Art. 6º).

0 artigo $2^{\circ}$ da lei em pauta determina que o SME/SM deverá ser integrado pelas instituições: Secretaria Municipal de Educação; Conselho Municipal de Educação; Escolas Municipais de Ensino Fundamental; Instituições de Educação Infantil mantidas pelo Poder Público Municipal e pela iniciativa privada; Escolas de Ensino Profissionalizante da rede municipal (SANTA MARIA, 1997b).

Em Santa Rosa, através da Lei Municipal no 3.211 (SANTA ROSA, 1999a), são fixadas as atribuições e responsabilidades de cada órgão constituinte do SME. Em 2009, no entanto, o Poder Executivo encaminha um projeto de lei ao legislativo com a finalidade de integrar o sistema educacional no conjunto da estrutura administrativa geral da Prefeitura Municipal, o que é aprovado sob a forma da Lei Municipal no 4.477 (SANTA ROSA, 2009b). Nesta legislação todo o núcleo administrativo da prefeitura municipal é apresentado, através de: órgão colegiado; órgãos de assessoramento e coordenação; órgãos auxiliares; órgãos de administração específica e órgãos de participação e representação, dentre os quais se incluem 27 conselhos municipais representativos de diferentes áreas sociais, onde se inclui o CME.

0 Art. 28 da lei em questão referenda que o SME/SR compreende: as instituições de ensino fundamental e de educação infantil, mantidas pelo poder público municipal; as instituições de educação infantil, criadas e mantidas pela iniciativa privada não ligadas ao ensino regular; a Secretaria Municipal de Educação e Juventude - SMEJ - ; o Conselho Municipal de Educação e o núcleo de assessoramento e apoio do Sistema Municipal de Ensino (SANTA ROSA, 2009b).

Esta nova organização da gestão administrativa da Prefeitura Municipal de Santa Rosa, fixada pela legislação de 2009, apresenta sérios comprometimentos no que diz respeito à autonomia do Sistema Municipal de Ensino, tendo em vista que o mesmo é concebido como integrante da estrutura administrativa básica da Prefeitura Municipal na sua totalidade. Isto se afirma, considerando que, nesta configuração, a Secretaria Municipal de Educação e Juventude (SMEJ) é excluída do atual modelo de gestão, não tendo representatividade como órgão de administração específica, tal como são destacadas as demais secretarias municipais. Nesta dinâmica se perde a identidade legal, tanto do SME, quanto da SMEJ por não haver lei específica para a organização da educação no município. 
Isto evidencia equívocos ao considerar o SME como órgão executor das políticas educacionais no âmbito do município, isentando a SMEJ desta responsabilidade. Salienta-se a importância da SMEJ por ser a unidade executora das políticas planejadas pelos órgãos que compõem o SME, em especial o Conselho Municipal de Educação.

Dadas as peculiaridades dos Sistemas Municipais de Educação dos municípios em análise, os respectivos Conselhos de Educação também têm suas especificidades. Nesta dinâmica de atendimento dos preceitos constitucionais, é fundamental, pela natureza democrática que deverá assumir o CME, a participação da comunidade na organização, na composição e na delimitação de atribuições a este órgão do poder local referente à educação municipal na definição, normatização e controle dos assuntos educacionais.

\section{Os Conselhos Municipais de Educação em foco: criação, composição e representação social}

A Lei Municipal no 4.122 (SANTA MARIA, 1997a), que "dispõe sobre o Conselho Municipal de Educação e dá outras providências", regulamenta este órgão tendo em vista adequá-lo ao SME, atendendo aos dispositivos expressos na LDB (BRASIL, 1996). Salientase que o CME em Santa Maria foi criado, inicialmente, pela Lei Municipal n 3.168/1989. No decorrer do tempo sofreu alterações, como a que ocorreu em 1996, momento em que a lei de 1989 foi substituída pela Lei Municipal no 3.956 (SANTA MARIA, 1996, grifo do autor), lei esta que evidenciava, ainda, uma extrema dependência das decisões do Sistema Estadual, como se pode observar em seu artigo $9^{\circ}$, alínea c que estabelece "critérios para ampliação da rede de escolas a serem mantidas pelo Poder Público Municipal, tendo em vista as diretrizes tratadas no PLANO ESTADUAL DE EDUCAÇÃO".

Em 1997, em consonância com a recente aprovação da LDB (BRASIL, 1996) e sua ênfase nos Sistemas Municipais de Educação, altera-se novamente a lei que regulamenta o CME/SM. Revogam-se as leis de 1989 e 1996, passando este órgão colegiado a ser regulamentado pela Lei $n^{\circ} 4.122$ (SANTA MARIA, 1997a, Art. 10, grifo nosso), em vigor, lei esta que vincula o CME à Secretaria Municipal de Educação de Santa Maria e estabelece que:

0 Conselho, criado pela Lei Municipal n³168/89, passa a denominar-se Conselho Municipal de Educação de Santa Maria - CMESM, órgão de política educacional, administrativamente autônomo, de caráter consultivo, normativo, deliberativo e fiscalizador acerca dos temas que forem de sua competência, vinculado a Secretaria de Município da Educação.

0 art. $2^{\circ}$ da referida lei determina a constituição do CME/SM, devendo 0 mesmo ter nove membros titulares e nove suplentes (SANTA MARIA, 1997a, Art. $2^{\circ}$ ). Dos nove membros titulares, dois terços (2/3) deverão ser compostos de 
professores do ensino público e particular, nomeados pelo Poder Executivo Municipal (Quadro 2), o que parece sofrer, ainda, forte influência do Sistema Estadual que se configurou no período ditatorial civil-militar, visto que, através da Lei Estadual no 5.751 de maio de 1969, que instituiu o Sistema Estadual de Ensino do Rio Grande do Sul, em seu artigo 15 estabelece que as leis municipais poderiam criar um $\mathrm{CME}$, o qual deveria ser integrado por 2/3, no mínimo, de professores do ensino público e particular (WERLE, 2006).

Por sua vez, o CME/SR, constituído por 21 membros titulares e 21 suplentes (Quadro 2), atualmente tem suas ações embasadas na Lei Municipal no 4.530, de 20 de maio de 2009 - que consolida a legislação municipal da educação. Observa-se, no entanto, que o CME/SR já havia sido criado em 1990, pela Lei Municipal n 2.258 de 23 de agosto, num período anterior à aprovação da LDB/96 e, reestruturado, quando da criação do SME/SR, através da Lei Municipal nº 3.212 (SANTA ROSA, 1999b).

Sobre a constituição dos CMEs no Rio Grande do Sul, é importante observar a pesquisa realizada por Werle (2006) ao apontar a predominância de Conselhos com nove membros, caso de Santa Maria e, em menor proporção, os Conselhos com maior número de representantes, caso de Santa Rosa.

A maioria dos $\mathrm{CME}_{1}$ 60\%, têm 9 membros. Não somam 20\% os municípios cujos CME são compostos por mais de 10 componentes - 8,75\% têm 12 membros, 6,25\% são compostos por 15 membros, chegando um deles a ter 16 membros e outro, 18 componentes (WERLE, 2006, p. 352).

Na mesma linha dos estudos de Werle (2006) referentes à composição de CMEs no RS, Bordignon (2009), apresentando dados referentes ao panorama nacional dos Sistemas de Ensino, referenda que a média brasileira de representantes nos CME se situa na faixa de nove membros, havendo, no entanto, variações que vão de dois até 32 membros.

Sobre a representação social nos CME, é importante observar com Bordignon (2009, p. 69) que esta deve se fundamentar-se em uma "visão de totalidade a partir dos olhares dos conselheiros desde os diferentes pontos de vista da sociedade". Neste sentido, o foco de ação dos conselheiros com representação neste órgão colegiado deverá estar sempre voltado para a qualidade do ensino, para o aluno e para o interesse coletivo.

0 Quadro 2 é revelador do cenário da composição e da representação social existente nos dois Conselhos Municipais de Educação em análise. Observa-se que, para fins de esclarecimento, em uma perspectiva comparativa, os integrantes dos referidos conselhos foram agrupados por entidades representativas da sociedade. 
Quadro 2: Constituição e representação social dos Conselhos Municipais de Educação, dos municípios de Santa Maria/RS e de Santa Rosa/RS.

\begin{tabular}{|c|c|}
\hline \multicolumn{2}{|c|}{ CONSTITUIÇÃO E REPRESENTAÇÃO SOCIAL } \\
\hline \begin{tabular}{|l|} 
Santa Maria/RS \\
09 membros titulares e 09 suplentes
\end{tabular} & $\begin{array}{l}\text { Santa Rosa/RS } \\
21 \text { membros titulares e } 21 \text { suplentes }\end{array}$ \\
\hline $\begin{array}{l}\text { Entidades Educacionais: } 01 \\
\text { representante indicado pela } \\
\text { Universidade Federal de Santa } \\
\text { Maria, ligados ao Centro de } \\
\text { Educação; }\end{array}$ & $\begin{array}{l}\text { Entidades Educacionais: } \\
03 \text { (três) representantes escolhidos pela entidade } \\
\text { representativa dos Professores Municipais, sendo } 02 \text { (dois) } \\
\text { professores e } 01 \text { (um) funcionário de escola; } 01 \text { (um) } \\
\text { representante da Educação Especial; } 01 \text { (um) representante do } \\
\text { Ensino Superior, indicado pela UNIJUí - Campus Santa Rosa e } \\
\text { pela FEMA; } 01 \text { (um) representante das escolas particulares. }\end{array}$ \\
\hline $\begin{array}{l}\text { Poder Público: a) municipal: } 04 \\
\text { representantes indicados pela } \\
\text { Secretaria Municipal de Educação; } \\
\text { b) Estadual: } 01 \text { representante } \\
\text { indicado pela } 8^{\text {a }} \text { Coordenadoria } \\
\text { de Educação do Estado. }\end{array}$ & $\begin{array}{l}\text { Poder Público: a) municipal: } 02 \text { (dois) representantes da } \\
\text { Prefeitura Municipal; } \\
\text { b) Estadual: um representante da } 17^{\text {a }} \text { Coordenadoria } \\
\text { Regional de Educação; }\end{array}$ \\
\hline $\begin{array}{l}\text { Entidades de Alunos: } \\
\text { Não contempla }\end{array}$ & $\begin{array}{l}\text { Entidades de Alunos: } 01 \text { (um) aluno representando os } \\
\text { estudantes do Município, através de sua entidade (USES); } \\
01 \text { (um) acadêmico representando os Diretórios Acadêmicos, } \\
\text { escolhidos entre os seguintes diretórios: Diretório } \\
\text { Acadêmico Paulo Freire (DAPAFRE) e Diretório Acadêmico } \\
\text { Leandro Rosa (DALERO) da UNIJUÍ - Campus Santa Rosa) e } \\
\text { do Diretório Irmão Otão e Diretório Augusto Rodrigues da } \\
\text { Fundação Educacional Machado de Assis (FEMA). }\end{array}$ \\
\hline $\begin{array}{l}\text { Entidades de Pais: } \\
\text { Não contempla }\end{array}$ & $\begin{array}{l}\text { Entidades de Pais: } 02 \text { (dois) representantes de pais de } \\
\text { alunos, indicados através de suas entidades, um escolhido } \\
\text { pela Associação de Círculo de Pais e Mestres Regional de } \\
\text { Escolas Públicas (ACPMR) e um pelo Círculo de Pais e } \\
\text { Mestres das Escolas Particulares (CPM); }\end{array}$ \\
\hline $\begin{array}{l}\text { Entidades Sindicais: } 01 \text { representante } \\
\text { indicado pelo Sindicato dos } \\
\text { Estabelecimentos Particulares de } \\
\text { Ensino, Delegacia de Santa Maria } \\
\text { (SINEPE); } 01 \text { representante indicado } \\
\text { pelo Sindicato dos Professores } \\
\text { Municipais de Santa Maria } \\
\text { (SIMPROSM); }\end{array}$ & $\begin{array}{l}\text { Entidades Sindicais: } 01 \text { (um) representante escolhido pela } \\
\text { entidade representativa do } 10^{\circ} \text { Núcleo CPERS/SINDICATO; } \\
01 \text { (um) representante indicado pela entidade } \\
\text { representativa do Sindicato dos Professores de Escolas } \\
\text { Particulares do Rio Grande do Sul (SINPRO-RS); } 01 \text { (um) } \\
\text { representante do Sindicato dos Trabalhadores Rurais; } 01 \\
\text { (um) representante dos Trabalhadores Urbanos. }\end{array}$ \\
\hline $\begin{array}{l}\text { Entidades ligadas à Indústria, } \\
\text { Comércio e Serviços: } \\
\text { Não contempla }\end{array}$ & $\begin{array}{l}\text { Entidades ligadas à Indústria, Comércio e Serviços: } 01 \text { (um) } \\
01 \text { (um) representante do SESI; } 01 \text { (um) representante do } \\
\text { SENAI; } 01 \text { (um) representante do SESC-SENAC; } \\
01 \text { (um) representante ACISAP. }\end{array}$ \\
\hline \begin{tabular}{l|} 
Associações Comunitárias: 01 \\
representante indicado pela União \\
das Associações Comunitárias (UAC).
\end{tabular} & $\begin{array}{l}\text { Associações Comunitárias: } \\
\text { Não contempla }\end{array}$ \\
\hline
\end{tabular}

Fonte: Santa Maria (1997a) e Santa Rosa (2009a). 
As diferenças de representação da sociedade organizada nos respectivos CMEs de Santa Maria e Santa Rosa não obedecem às características peculiares destes municipios. Esta afirmação pode ser observada, por exemplo, no aspecto referente à densidade demográfica, tendo como base dados do último Censo Demográfico (IBGE, 2010). Santa Maria, situada entre os cinco maiores municipios gaúchos, possuindo 261.027 habitantes tem, em seu CME, uma representação de apenas nove membros titulares e nove suplentes, sem maior participação social, especialmente de membros da comunidade escolar. Santa Rosa, município com população de 68.595 habitantes, tem uma representação de 21 membros titulares e 21 suplentes em seu $\mathrm{CME}$, o que contempla uma vasta gama de setores sociais.

Salienta-se que na constituição do CME de Santa Maria, além dos nove titulares e seus respectivos suplentes e, dentre eles, quatro serem representantes da Secretaria Municipal de Educação (SMEd), como consta no art. $2^{\circ}$ da lei em questão (SANTA MARIA, 1997a), o art. 13 determina a existência de mais dois professores $d a$ rede municipal a serem nomeados pelo Poder Público Municipal para as funções de Secretário Executivo e Assessor Técnico do CME/SM, o que totaliza 6 membros do Poder Executivo na estrutura do Conselho Municipal de Educação de Santa Maria, sinalizando para um centralismo de poder da SMEd no referido Conselho. Diferentemente, em Santa Rosa, além dos 21 membros titulares, a assessoria do CME é feita por um Assessor Técnico em Assuntos Educacionais, integrante do Sistema Municipal de Ensino e por um Assessor Administrativo.

Destaca-se este aspecto, considerando que a função de assessoramento é, sem dúvida, vinculada à atribuições de caráter técnico-administrativo, mais que de simples execução de tarefas administrativas, o que requer conhecimentos e capacidades especificas de quem as realiza.

Isto nos leva a refletir esta função no CME de Santa Maria, especialmente, tendo em vista que, ao definir que dois terços (2/3) deste órgão serão compostos por professores, questiona-se o fato do Secretário Executivo e Assessor Técnico do CME/SM serem, também, professores, tendo em vista as funções de caráter consultivo, normativo, deliberativo e fiscalizador que assume este órgão, o que exigiria pessoal técnico para assessorar melhor o CME diante destas funções. Observa-se a importância da atuação destes profissionais devendo os mesmos serem especializados, tendo em vista a organização dos CMEs no que diz respeito às funções a serem desempenhadas no acompanhamento das discussões junto às plenárias e comissões, assessorando a elaboração de pareceres, normativas e demais atos legais expedidos pelo órgão nas suas diferentes atribuições.

A importância da atuação técnica pode ser exemplificada quando do exercício da função fiscalizadora da aplicação de recursos que deverá ser desempenhada, tanto junto às escolas, como junto às próprias Secretarias de Educação, tendo em vista a 
descentralização de recursos públicos para a educação pelas atuais políticas de gestão na área educacional. Este aspecto é posto em relevo por ser a questão financeira excessivamente complexa, considerando as várias fontes e montantes de recursos públicos para a educação, o que exige monitoramento e controle por parte da sociedade representada nos CMEs. Um assessoramento mais especializado em financiamento e contabilidade sinaliza para melhor desempenho dos Conselhos nesta função.

Este fato leva a outro relacionado à representação de demais órgãos e segmentos organizados da sociedade, ausentes na constituição dos Conselhos em análise, mas importantes fontes de informação para tomada de decisões. Em Santa Maria percebe-se a limitação da representação social no CME, salientando-se, aqui, a ausência do Conselho do Fundef, agora, Fundeb; representação dos Círculos de Pais e Mestres (CPM); de Conselhos Escolares; de Grêmios Estudantis, bem como a ausência dos demais ConseIhos ligados à educação, tais como Conselho Tutelar; Conselho de Alimentação Escolar; Conselho Municipal dos Direitos da Criança e do Adolescente. A estes, acresce-se a ausência de representação do Conselho Municipal de Saúde, levando em conta o compromisso deste órgão com a saúde da criança em idade escolar, como determina a Lei Municipal no 5.023 (SANTA MARIA, 2007, p. 1) que "Autoriza o Poder Executivo Municipal a criar o Programa de Prevenção e Controle do Diabetes em Crianças e Adolescentes Matriculados nas Escolas da Rede Pública Municipal de Ensino".

Em Santa Rosa, praticamente se reproduz o que acontece em Santa Maria, mas com uma dinâmica diferenciada, tendo em vista que a Lei Municipal no 4.477 (SANTA ROSA, 2009b), em seu artigo 10, institui o CME como um dos órgãos de participação e representação do município, sendo este vinculado ao Sistema Municipal de Ensino ao lado de outros colegiados como o Conselho Municipal de Controle Social, o Conselho Municipal de Alimentação Escolar e o Conselho Municipal de Acompanhamento e Controle Social do Fundo de Manutenção do Desenvolvimento do Ensino Fundamental e de Valorização do Magistério. Este último, inscrito na Lei Municipal de 2009, ainda é identificado como Fundo de Manutenção e Desenvolvimento do Ensino Fundamental e de Valorização do Magistério (Fundef) - mantendo uma nomenclatura desatualizada em relação à lei que cria o Fundo de Manutenção e Desenvolvimento da Educação Básica e de Valorização dos Profissionais da Educação (Fundeb) (BRASIL, 2007). No entanto, é importante observar que os conselhos citados não estão representados na composição do CME/SR a exemplo do que ocorre em Santa Maria, o que macula a representatividade social, tornando dúbia a ideia de democratização deste colegiado.

A falta de participação social compromete a democratização deste órgão como, efetivamente, representativo da sociedade e das decisões em cada área de sua competência, situação que poderá estar implicada em uma realidade maior, cujas resistências se dão por relações de poder, parecendo corresponder ao que Bordignon ([2010?], não paginado, grifo do autor) afirma: 
A relação entre os conselhos e os órgãos de gestão da estrutura dos sistemas de ensino tem registrado tensões, conflitos e rupturas na sua trajetória. Tensões e movimentos de cooperação e de conflitos, de ampliação e estreitamento da autonomia, de centralização e descentralização. Conflitos originados por questões de ordem cultural e estrutural. 0 conflito cultural advém da cultura de poder no Brasil, radicada no positivismo, que situa o dirigente (dotado de saber e razão superior) como sujeito da ação e o alvo dessa ação como objeto - incluídos no objeto fins, meios, educadores e educandos.

Para Werle (2006, p. 352-353, grifo nosso), a restrita representatividade da sociedade organizada no Conselho poderia ser contrabalançada por uma assessoria especializada:

0 número de componentes é relevante, pois está relacionado com a possibilidade de diversificação da origem e representação de seus membros - sociedade civil local, dos professores e dos pais ou do poder executivo local, dentre outras. [...] Caso o colegiado conte com assessores técnicos qualificados, entretanto, um número mais restrito de componentes possivelmente não traga dificuldades de funcionamento. Se estas hipóteses são de ordem técnica, o maior número de componentes pode justificar-se do ponto de vista político. Um colegiado com maior número de componentes favorece uma diversificada representação de entidades da sociedade civil e da comunidade escolar.

Esta posição não é pactuada por Bordignon, ao afirmar que "conselhos muitos pequenos não chegam a se caracterizar como conselhos, uma vez que a pluralidade social e o diálogo interpares ficam muito limitados" (BORDIGNON, 2009, p. 74). Deste modo, cada município deve adequar o número de vagas às suas caracteristicas peculiares.

Sem a devida representação social se centraliza o poder nas mãos de poucos, retirando o caráter democrático do CME. Isto se observa, especialmente em Santa Maria, município em que o CME tem em seu quadro seis membros designados pelo poder público através da SMEd (quatro professores efetivos e dois professores com funções técnico-administrativas), representando $66 \%$ do total de membros integrantes do $\mathrm{CME}_{\text {, correspondendo ao }}$ que Bordignon ([2010?], não paginado, grifo nosso) aponta como "políticas públicas (que) tendem a assumir a visão de mundo singular da 'autoridade', culturalmente 'autorizada' a assumir o poder de definir os rumos das aspirações da sociedade".

Isto posto incita a um questionamento importante: "conselhos de sábios ou de representação popular?" (BORDIGNON, 2009, p. 68, grifo do autor). 
Para o autor ambos são necessários, pois:

[...] a composição dos conselhos precisa ser constituída por representantes da pluralidade social, aliando o saber acadêmico ao saber popular. A ação dos conselheiros, porque chamados a opinar e deliberar sobre políticas educacionais, normas, processos pedagógicos, requer saberes - acadêmico e da vivência social ambos sempre com percepção política das aspirações sociais. Assim, a composição dos conselhos passa a requerer não somente o saber letrado, mas a expressão da pluralidade dos saberes da diversidade social (BORDIGNON, 2009, p. 68, grifo do autor).

Neste cenário, o efetivo predomínio de representantes indicados pelo poder público em Santa Maria questiona o artigo $4^{\circ}$ da lei em pauta (SANTA MARIA, 1997a, grifo nosso) pelo qual "não poderão compor o colegiado deste Conselho, pessoas detentoras de cargos de confiança do Executivo Municipal".

As contradições que envolvem as leis municipais de Santa Maria e Santa Rosa quanto à representação social, indicam diferentes condições de atuação do CME como agente de inovação no que diz respeito às políticas públicas que, no entendimento de Gonh (2001), deveriam realizar a mediação entre a sociedade civil organizada e os organismos governamentais, de modo a propiciar a construção de uma nova esfera pública de poder e de controle social que, por força de dinâmica representativa favorece o fortalecimento de novos sujeitos políticos.

\section{Atuação do CME: atribuições/competências fixadas em lei}

Uma vez que o Conselho Municipal de Educação passa a ser concebido como um organismo de participação da sociedade considera-se como extremamente importante que sua atuação seja exercida de modo qualificado e comprometido. Sob este prisma, a divisão das atribuições ou competências entre os órgãos do Sistema Municipal de Ensino, ou seja, o CME e a Secretaria Municipal de Educação possibilitam o desvelamento de como se caracteriza a divisão dos espaços decisórios entre ambos nas distintas atribuições que desempenham de acordo com os termos definidos em lei. Conforme se mostra a participação da comunidade no CME associa-se a isto uma divisão das responsabilidades de modo que o trabalho levado a efeito neste órgão colegiado possa se traduzir em respostas às demandas existentes na amplitude e complexidade do Sistema Municipal de Ensino.

Nesta perspectiva, no Quadro 03, são apresentadas as atribuições/competências dos Conselhos Municipais de Educação dos municípios de Santa Maria e de Santa Rosa, conforme as respectivas leis que embasam a ação destes CMEs. Para fins de apresentação, as atribuições do CME/SR foram unificadas em blocos, visando a verificar a correspondência às atribuições/competências do CME/SM. 
Constituição e funcionamento do Conselho Municipal de Educação frente ao processo de democratização da gestão: um estudo dos municípios de Santa Maria e Santa Rosa/RS

Quadro 3: Atribuições/ competências dos Conselhos Municipais de Educação, dos municípios de Santa Maria/RS e de Santa Rosa/RS.

\begin{tabular}{|c|c|}
\hline Santa Maria/RS & Santa Rosa/RS \\
\hline $\begin{array}{l}0 \text { art. } 10 \text { da Lei Municipal no } 4.122 / 1997 \\
\text { estabelece } 10 \text { atribuições e o art. } 11 \\
\text { estabelece } 06 \text { competências ao CME/SM. }\end{array}$ & $\begin{array}{l}0 \text { art. Art, } 7^{\circ} \text { da Lei } n^{\circ} 4.530 \text { de 20/05/2009 } \\
\text { (Consolidação da Legislação Educacional } \\
\text { municipal) estabelece } 22 \text { atribuições ao CME/SR. }\end{array}$ \\
\hline $\begin{array}{l}\text { Art. } 10 \text { - elaborar e/ou reformular seu } \\
\text { Regimento Interno a ser aprovado pelo } \\
\text { Poder Executivo Municipal; }\end{array}$ & Não contempla \\
\hline $\begin{array}{l}\text { - participar na discussão do Plano } \\
\text { Municipal de Educação - PME - do } \\
\text { municipio e aprová-lo; }\end{array}$ & $\begin{array}{l}\text { - criar e garantir mecanismos de participação } \\
\text { efetiva e democrática da comunidade escolar na } \\
\text { definição do Plano Municipal de Educação; } \\
\text { - aprovar o Plano Municipal de Educação, nos } \\
\text { termos do art. 34, inciso III das Disposições } \\
\text { Transitórias da Constituição Estadual. } \\
\end{array}$ \\
\hline $\begin{array}{l}\text { - acompanhar e controlar a aplicação de } \\
\text { recursos públicos destinados à educação; } \\
\text { (grifos nossos) }\end{array}$ & $\begin{array}{l}\text { - tomar conhecimento e opinar sobre o Plano } \\
\text { Plurianual, Lei de Diretrizes Orçamentárias e } \\
\text { Orçamento da Educação; } \\
\text { - divulgar informações referentes à aplicação dos } \\
\text { recursos financeiros, resultados obtidos e qualidade } \\
\text { dos serviços prestados; } \\
\text { - acompanhar a distribuição das matrículas de } \\
\text { acordo com o aporte financeiro dos sistemas, em } \\
\text { regime de colaboração; }\end{array}$ \\
\hline $\begin{array}{l}\text { - propor medidas de atualização, } \\
\text { capacitação e aperfeiçoamento de } \\
\text { professores; }\end{array}$ & $\begin{array}{l}\text { - sugerir medidas e programas de atualização de } \\
\text { professores. }\end{array}$ \\
\hline $\begin{array}{l}\text { - fiscalizar o Sistema Municipal de Ensino, } \\
\text { ou conjunto de escolas municipais; (grifos } \\
\text { nossos) }\end{array}$ & $\begin{array}{l}\text { - propor políticas educacionais ao Município, bem } \\
\text { como acompanhar e avaliar sua execução; } \\
\text { - opinar sobre a proposta político-pedagógica das } \\
\text { escolas que compõem o Sistema Municipal de } \\
\text { Ensino; (grifos nossos) }\end{array}$ \\
\hline $\begin{array}{l}\text { - cumprir as atribuições que lhe forem } \\
\text { delegadas pelo Conselho Estadual de } \\
\text { Educação_CEE. (grifos nossos) }\end{array}$ & Não contempla \\
\hline $\begin{array}{l}\text { - manter intercâmbio com o Conselho } \\
\text { Estadual de Educação e demais Conselhos } \\
\text { Municipais de Educação. }\end{array}$ & $\begin{array}{l}\text { - manter intercâmbio com o Conselho Federal de } \\
\text { Educação, Conselho Estadual de Educação e com os } \\
\text { demais Conselhos Municipais de Educação; }\end{array}$ \\
\hline $\begin{array}{l}\text { - zelar pelo cumprimento das disposições } \\
\text { constitucionais, legais e normativas em } \\
\text { matéria de educação e ensino, } \\
\text { representando junto às autoridades } \\
\text { competentes, quando for o caso. }\end{array}$ & $\begin{array}{l}\text { - recorrer a instâncias superiores sobre questões } \\
\text { que não se julgar apto a de cidir e não previstas em } \\
\text { Lei; }\end{array}$ \\
\hline
\end{tabular}

Ensaio: aval. pol. públ. Educ., Rio de Janeiro, v. 19, n. 72, p. 651-678, jul./set. 2011 
Quadro (continuação)

\begin{tabular}{|c|c|}
\hline $\begin{array}{l}\text { - estabelecer critérios para conservação e, } \\
\text { quando necessário, a ampliação rede de } \\
\text { escolas a serem mantidas pelo Municipio. }\end{array}$ & $\begin{array}{l}\text { - propor critérios para a ampliação da rede de } \\
\text { escolas a serem mantidas pelo Município, tendo em } \\
\text { vista as normas traçadas na Lei de Diretrizes e } \\
\text { Bases da Educação Nacional; }\end{array}$ \\
\hline $\begin{array}{l}\text { - pronunciar-se quanto à criação e ao } \\
\text { funcionamento de estabelecimentos de } \\
\text { ensino público de qualquer nível a ser } \\
\text { instalado no município. }\end{array}$ & $\begin{array}{l}\text { - autorizar a criação de novos estabelecimentos de } \\
\text { ensino; }\end{array}$ \\
\hline Art 11. - Emitir parecer sobre: & - emitir pareceres; \\
\hline $\begin{array}{l}\text { - assuntos educacionais e questões de } \\
\text { natureza pedagógica que lhe forem } \\
\text { submetidas pelo Executivo ou Legislativo } \\
\text { Municipal e/ou por entidades de âmbito } \\
\text { municipal, ligadas à educação; }\end{array}$ & $\begin{array}{l}\text { - deliberar sobre planos e programas } \\
\text { administrativos e pedagógicos; } \\
\text { - baixar normas complementares de Sistemas de } \\
\text { Ensino; } \\
\text { - analisar e apreciar questões de interesse das } \\
\text { escolas quando lhe forem encaminhadas; }\end{array}$ \\
\hline $\begin{array}{l}\text { - funcionamento, ativação e desativação } \\
\text { de escolas públicas da rede municipal; }\end{array}$ & $\begin{array}{l}\text { - emitir parecer sobre o funcionamento das escolas } \\
\text { municipais; }\end{array}$ \\
\hline $\begin{array}{l}\text { - alteração de bases curriculares, } \\
\text { regimentos escolares, calendário escolar, } \\
\text { pré-escola e avaliação; }\end{array}$ & $\begin{array}{l}\text { - aprovar bases curriculares; } \\
\text { - aprovar regimentos escolares; }\end{array}$ \\
\hline $\begin{array}{l}\text { - a criação de novas escolas, séries e/ou } \\
\text { cursos a serem mantidos pelo Municipio; }\end{array}$ & $\begin{array}{l}\text { - aprovar ampliação de séries; } \\
\text { - autorizar a criação de novos estabelecimentos de } \\
\text { ensino; }\end{array}$ \\
\hline $\begin{array}{l}\text { - concessão de auxilio e subvenções às } \\
\text { instituições educacionais; }\end{array}$ & Não contempla \\
\hline $\begin{array}{l}\text { - convênios, acordos e similares a serem } \\
\text { celebrados pelo Poder Público Municipal } \\
\text { com as demais instâncias governamentais } \\
\text { e não-governamentais. }\end{array}$ & Não contempla \\
\hline Não contempla & $\begin{array}{l}\text { - participar dos estudos da comunidade local, } \\
\text { tendo em vista os problemas educacionais; (grifos } \\
\text { nossos) }\end{array}$ \\
\hline Não contempla & $\begin{array}{l}\text { - avaliar e implementar medidas para a melhoria e } \\
\text { aperfeiçoamento do rendimento escolar; }\end{array}$ \\
\hline
\end{tabular}

Fonte: Santa Maria (1997a) e Santa Rosa (2009a). 
Do total de atribuições ou competências para os CMEs acima expostas, algumas merecem atenção frente à necessidade de conhecimento especializado e permanente atualização das políticas educativas. Salienta-se este aspecto, visto que em Santa Maria, por exemplo, dentre as atribuições do CME, seus membros deverão participar na discussão do Plano Municipal de Educação (PME) e aprová-Io; acompanhar e controlar a aplicação de recursos públicos destinados à educação; propor medidas de atualização, capacitação e aperfeiçoamento de professores; fiscalizar o Sistema Municipal de Ensino, ou conjunto de escolas municipais; e cumprir as atribuições que Ihe forem delegadas pelo Conselho Estadual de Educação (CEE).

Estas atribuições podem ser questionadas na prática do CME/SM, considerando a íntima ligação deste órgão com o Poder Executivo, o que lhe retira autonomia para cumprir suas atribuições com isenção de influências de outros órgãos, assim como, impossibilita a autonomia municipal como Sistema de Educação, tendo em vista sua dependência ao CEE, devendo o mesmo "cumprir as atribuições que lhe forem delegadas pelo Conselho Estadual de Educação" (SANTA MARIA, 1997a, Art. 10, h, grifo nosso), situação que reproduz as propostas de leis anteriores (SANTA MARIA, 1989, 1996), quando da criação do CME em Santa Maria.

Nesta perspectiva, a lei que dispõe sobre o CME/SM se encontra defasada em relação à Constituição Federal (BRASIL, 1988), pois ao expressar a dependência do Sistema Estadual, inviabiliza a existência de seu próprio sistema, deixando o CME impedido de cumprir com as funções que Ihe são inerentes como órgão de caráter consultivo, normativo, deliberativo e fiscalizador. Com isto se perde a autonomia administrativa deste órgão do SME/SM.

Em Santa Rosa, a observação das 22 competências estabelecidas em lei denota que a maioria delas se vincula a uma essência meramente burocrática, credencialista e operacional, o que não se diferencia das competências atribuídas ao CME em Santa Maria. Por sua vez, há avanços em seu processo de democratização, visto o entrelaçamento com a comunidade, quando o CME se insere como articulador de interesses coletivos e, conjuntamente, busca respostas às questões que emergem do contexto social. Sobre isto pode-se exemplificar as competências explícitas relacionadas aos estudos com a comunidade, tendo em vista os problemas educacionais e o envolvimento com as escolas no sentido de opinar sobre as Propostas Pedagógicas, entre outras relacionadas ao envolvimento comunitário. Aponta-se, entretanto, a falta de referência à elaboração do Regimento Interno deste órgão, ainda que esta seja uma importante atribuição do mesmo, considerando que este documento normatiza a ação dos CME. 


\title{
Regimento Interno do CME: organização e operacionalização do órgão colegiado
}

Através do Regimento Interno do CME, tanto em Santa Maria (1998) quanto em Santa Rosa, (2003) são definidas as comissões nas quais assuntos de interesse específico são detalhados visando à operacionalização das atribuições do próprio CME.

0 Regimento Interno do CME de Santa Maria (1998) está dividido em oito capítulos. Em seu texto, mantém a mesma composição proposta na Lei n ${ }^{0} 4.122$ (SANTA MARIA, 1997a, Cap. II). Apresenta, no entanto, divergências com as determinações da referida lei, ampliando suas atribuições e competências. Exemplos claros desta afirmação são as atribuições de

\begin{abstract}
'coordenar o processo de definições de políticas e diretrizes municipais da educação'; 'avaliar a realidade educacional do município e propor medidas ao Poder Executivo com vistas a melhoria do processo educacional'; 'aprovar o relatório anual da SMEd que incluirá dados sobre a execução financeira' (SANTA MARIA, 1998, Art. $7^{\circ}$, Cap. III, grifo nosso).
\end{abstract}

É importante salientar que, do conjunto de atribuições e competências do CME/SM, o Regimento omite a dependência das determinações do CEE, o que é salutar no sentido de resguardar a autonomia municipal, mesmo ferindo a lei que cria o CME/SM. Por sua vez, não há também, nenhuma atribuição relacionada ao acompanhamento do orçamento público para a educação de modo que o Conselho possa exercer sua função de "acompanhar e controlar a aplicação de recursos públicos destinados à educação" como expressa a lei do CME/SM (SANTA MARIA, 1997a, grifo nosso), a partir da realidade concreta.

0 Regimento (SANTA MARIA, 1998) estabelece em sua estrutura, além dos membros definidos em lei, duas comissões, compostas por três integrantes em cada uma: I. Comissão de Ensino; II. Comissão de Planejamento, Legislação e Normas (Art. $8^{\circ}$, Capítulo IV). É importante salientar que estas comissões não são eleitas por seus pares e sim designadas pela Presidência do Conselho (Art. 13, IV, Seção II, Capítulo IV). Os únicos cargos eletivos são para Presidente e Vice-Presidente com mandato de dois anos, podendo serem reconduzidos (Art. 10, Seção I, Capítulo IV). Neste aspecto, observa-se a omissão do Regimento quanto ao número e o prazo de interstício para reconduções, podendo, inclusive, conforme interpretação, tornar-se cargo vitalício.

0 Regimento do CME de Santa Rosa (2003), por sua vez, ainda que não tenha sua elaboração configurada entre as atribuições deste órgão, como já citado, é, na prática, elaborado pelo próprio CME. Formado em sua estrutura por nove capítulos, mantém-se ainda atrelado à lei de criação do CME de 1999, carecendo de atualização de modo a adequar-se à legislação atual. 
Todas as competências expostas na lei de criação do CME/SR e referendadas no Regimento, por sua complexidade, exigem uma ação responsável deste órgão. Deste modo para o pleno desenvolvimento do trabalho o $\mathrm{CME} / \mathrm{SR}$ opera através do Plenário, de Comissões Permanentes e de Comissões Especiais, conforme apresenta o capitulo V do Regimento, indicando, no Art. 28, que o Conselho Municipal de Educação, tem como Comissões Permanentes: a) Legislação e normas; b) Educação Infantil; c) Ensino Fundamental e Educação de Jovens e Adultos. Atualmente, constata-se a atuação da Comissão de Educação Especial, criada para atender permanentemente as demandas desta área, ainda que não esteja contemplada na estrutura do CME e careça de normatização, o que deverá ocorrer quando da revisão e reelaboração do novo Regimento Interno. Cada comissão permanente é constituída por, no mínimo, sete membros que escolhem entre si um presidente, um secretário e o relator da comissão. Comissões especiais podem ser criadas, para fins específicos, por solicitação dos conselheiros e com aprovação da maioria simples de votos (Art. 32 do Regimento Interno do CME/SR), sendo que essas comissões terão estrutura e funcionamento idêntico às comissões permanentes devendo, porém, ao serem constituídas, estabelecer o prazo necessário para a conclusão de sua tarefa e apresentar o respectivo relatório, após o que, estas comissões serão automaticamente dissolvidas.

Ainda que o poder público possa indicar representantes como conselheiros titulares ou suplentes, o artigo 15 do Regimento Interno do CME/SR veda a participação destes sujeitos na Diretoria Executiva deste órgão (Presidente, Vice-presidente e Secretário), quando detentores de função gratificada do Executivo Municipal, Estadual ou Federal, ou de cargos em comissão, assim como pessoas investidas de mandato legislativo. A exceção a isto cabe aos diretores de escola eleitos por voto direto, mesmo com função gratificada. Quanto ao mandato da diretoria executiva o regimento é claro ao apontar o período de dois anos com apenas uma recondução.

Observam-se nos Regimentos dos respectivos CME de Santa Maria (1998) e Santa Rosa (2003) situações que os diferenciam, tanto pelo número de comissões, quanto pela composição das mesmas, o que permite uma ação mais efetiva do Conselho de Santa Rosa frente ao compromisso deste órgão na consolidação do Sistema de Ensino. Em Santa Maria as limitações são mais evidentes frente à demanda do próprio município, pois enquanto Santa Rosa apresenta uma estrutura mais sólida na organização do CME de modo a atender as demandas de 28 escolas municipais com um total 5.114 alunos (INEP, 2010a), Santa Maria com uma estrutura limitada de seu CME, deverá atender as exigências de sua rede municipal integrada por 80 escolas e 15.676 alunos (INEP, 2010b) o que sinaliza para a frágil estrutura do SME do referido município. Isto se agrava quando se observam as inúmeras e complexas atribuições a serem cumpridas pelo CME/SM frente à sua precária estrutura. 


\section{Considerações finais}

0 modelo de Estado neoliberal que se instala no Brasil nos anos 1980 e se afirma nos anos 1990 - se reflete na Constituição Federal (BRASIL, 1988), em vigor, suscitando importantes mudanças na organização da educação, o que, naturalmente, interfere na legislação educacional. Afirmando a necessidade de normas mais adequadas às transformações ocorridas no país nos anos 80 - apesar da forte herança autoritária e centralizadora do período ditatorial, os movimentos de descentralização do Estado coincidem com os movimentos sociais, requerendo a democratização do país. A despeito das tensões político-sociais e partidárias que se faziam presentes desde a Constituinte, a Carta Magna (BRASIL, 1988) traz a municipalização como decorrência do processo descentralizador e culmina, em termos educacionais, com o Sistema Municipal de Educação, proposta que se consolida com a Lei de Diretrizes e Bases da Educação Nacional (BRASIL, 1996).

Com a municipalização, os SMEs deveriam constituir-se como organizações independentes e autônomas, cujas regulamentações e normas seriam previstas por seus próprios órgãos normativos, dentre os quais se destaca o CME como órgão consultivo, normativo, deliberativo e fiscalizador do sistema.

Neste enfoque, a análise sobre a organização dos Conselhos de Educação no país evidenciou que os mesmos foram originalmente concebidos com a exclusiva tarefa de assessoramento ao Governo, sendo os conselheiros escolhidos pelo Poder Executivo que se valia de critérios de notório saber educacional e de representatividade dos diferentes graus de ensino para definir a composição deste órgão.

Frente ao novo contexto da gestão democrática da educação, este paradigma é revisitado e critérios de representatividade social passam a ser preconizados como ideais para a composição dos Conselhos de Educação.

A discussão em torno da institucionalização e ordenamento legal do Conselho Municipal de Educação como espaço público de participação pressupõe um debate amplo, envolvendo a comunidade em seus diferentes segmentos. Isto dimensiona um processo de democratização da educação que não se dá apenas no sentido de cumprimento de disposições burocráticas ou legislativas como campo político, mas se entrelaça às concepções de cultura, educação e sociedade. Destarte, a representatividade social nas definições, normatizações e acompanhamento das políticas educacionais tendem a qualificar a ação do CME de modo a efetivar o Sistema Municipal de Ensino.

Diante deste cenário, a realidade educacional de Santa Maria e Santa Rosa no contexto da municipalização traz diferenciações e ambiguidades na organização de seus Sistemas de Ensino, evidenciando que a democratização das relações sociais, no campo da educação, depende de efetiva representação e participação nos órgãos normativos dos sistemas, com especial atenção ao CME. 
As contradições legais do SME de Santa Maria/RS, tratadas neste texto, possibilitam questionar a existência real de um Sistema de Educação Municipal, bem como a democratização de seu órgão máximo, o CME. Isto, no entanto, não se constitui um problema isolado como demonstram as muitas pesquisas sobre esta temática, entre elas os estudos de Werle (2006), nos quais a autora demonstra que os CME são colegiados constituídos com poucos componentes, cuja autonomia se perde por ser um órgão ocupado largamente pelo poder político, o executivo local, evidenciando que os CMEs ainda não conseguiram atingir seus propósitos com vistas à garantia do direito e à qualidade da educação, considerando que "estes conselhos têm se caracterizado pelo reforço dos grupos no poder e por uma extrema burocratização, além da função legalista que tem pautado suas ações" (DALL'IGNA; GOULARTE; MARTINS, 1996, p.1).

0 município de Santa Rosa vem trilhando um caminho no sentido de ampliar os espaços participativos. Neste particular, se destaca o Conselho Municipal de Educação, órgão no qual a comunidade pode ser ouvida, onde suas demandas devem ser discutidas através de representantes de distintos segmentos, com vistas ao direcionamento das políticas públicas ao atendimento dos anseios sociais.

0 grande desafio do CME, tanto de Santa Maria, como o CME de Santa Rosa é funcionar de forma autônoma frente as suas inúmeras atribuições de modo a dar respostas que sinalizem à criação de novos caminhos para a educação pública municipal. Atuar de forma diferenciada em um cenário onde os conselhos se alinham a uma lógica meramente formal e burocratizada e onde muitos deles estão equivocadamente vinculados como órgão de assessoramento do poder governamental é, sem dúvida, uma meta a ser perseguida na busca da democratização deste espaço público.

Os estudos realizados nesta investigação demonstram que ainda há muito a avançar para que o poder local seja realmente representativo da sociedade e, neste, o CME atue em favor da consolidação de sistemas autônomos de educação em favor dos interesses da própria sociedade. Nesta caminhada é preciso ter presente que o processo descentralizador é regido pela lógica do mercado, o que leva ao entendimento que a descentralização posta pelo Estado mínimo pode ser corrompida pela desregulamentação dos sistemas.

Nesta perspectiva, ressalta-se a importância deste trabalho, cuja finalidade gravitou em torno da compreensão de estruturas intermediárias de administração da educação pública tendo como foco os Conselhos Municipais de Educação, e ao questionamento de seu papel democratizante e fomentador da participação da comunidade local como um espaço de debate público, visando à construção de uma educação de qualidade social. Isto salientou a importância da construção de Sistemas de Ensino democráticos, não só em sua estrutura interna e composição, como, principalmente, na função social que lhes cabe diante das múltiplas e complexas demandas sociais em nosso país. 


\section{Referências}

BORDIGNON, G. Gestão da educação no município: sistemas, conselho e plano?. São Paulo: Ed. Livraria Instituto Paulo Freire, 2009. (Educação Cidadã, v. 3).

. Passos para criar um Conselho: Conselho Municipal de Educação: colegiado da gestão democrática do Sistema. Brasilia, DF: UNCME, [2010?].

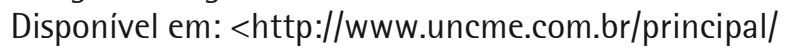
exibir_conteudo.asp?CO_AREA=7>. Acesso em: 9 dez. 2010.

BRASIL. Constituição (1934). Constituição da República dos Estados Unidos do Brasil. Rio de Janeiro, 1934. Disponivel em: <http://www.planalto.gov.br/ ccivil_03/constituicao/constitui\%C3\%A7ao34.htm>. Acesso em: 9 nov. 2010.

. Constituição (1946). Constituição dos Estados Unidos do Brasil. Diário Oficial da União, Rio de Janeiro, 25 set. 1946. Disponivel em: <http://www.planalto.gov.br/ ccivil_03/constituicao/constituicao46.htm>. Acesso em: 9 nov. 2010.

. Constituição (1988). Constituição da República Federativa do Brasil. Diário Oficial [da] República Federativa do Brasil, Brasilia, DF, 1988. Disponivel em: <http://www.planalto.gov.br/ccivil_03/constituicao/ constitui\%C3\%A7ao.htm>. Acesso em: 9 dez. 2010.

. Lei $n^{\circ}$. 4.024, de 20 de dezembro de 1961. Fixa as Diretrizes e Bases da Educação Nacional. Leis, Brasilia, 1961. Disponivel em: <http:// www.planalto.gov.br/ccivil_03/leis/l4024.htm>. Acesso em: dez. 2010.

. Lei $n^{0} .5 .692$, de 11 de agosto de 1971. Fixa Diretrizes e Bases para o ensino de $1^{\circ}$ e $2^{\circ}$ graus, e dá outras providências. Diário Oficial [da] República Federativa do Brasil, Brasília, DF, 12 ago. 1971. Disponivel em: <http:// www.planalto.gov.br/ccivil_03/leis/l5692.htm>. Acesso em: dez. 2010.

. Lei nº. 9.394, de 20 de dezembro de 1996. Estabelece as diretrizes e bases da educação nacional. Diário Oficial [da] República Federativa do Brasil, Brasília, DF, 1996.

. Lei no 11.494, de 20 de junho de 2007. Regulamenta o Fundo de Manutenção e Desenvolvimento da Educação Básica e de Valorização dos Profissionais da Educação - FUNDEB, [...]. Diário Oficial da Uniõo, Brasília, DF, 21 jun. 2007.

CURY, C. R. J. A educação escolar e o Sistema Nacional de Educação [entrevista]. [Brasilia, DF], 2008. Disponível em: <http://www.mover.ufsc.br/pedagogia/ Jamil\%201.pdf>. Acesso em: 9 nov. 2010. 
CURY, C. R. J. Os Conselhos de Educação e a gestão dos sistemas. In: FERREIRA, N. S.; AGUIAR, M. A. (Org.). Gestão da educação: impasses, perspectivas e compromissos. São Paulo: Cortez, 2000. p. 43-60.

DALL'LIGNA, M. A.; GOULARTE, G. F.; MARTINS, E. R. Conselhos Municipais de Educação: participação para quê?. In: REUNIÃO ANUAL DA ANPED, 19., 1996, Caxambu. Trabalhos apresentados... Caxambu: ANPED, 1996. 1 CD-ROM.

GADOTTI, M. Perspectivas atuais da educação. Porto Alegre: Artmed, 2000.

GOHN, M. G. Conselhos gestores e participação sociopolítica. São Paulo: Cortez, 2001.

IBGE. Cidades. Rio de Janeiro, 2010. Disponivel em: <http://www.ibge.gov.br/ cidadesat/topwindow.htm?1>. Acesso em 30 nov. 2010.

INEP. Dados de Santa Maria. Educacenso, Brasília, DF, 2010a. Disponível em: $<$ http://www.educasensomec.inep.gov.br/basica/censo/Escolar/Matricula/ censoescolar_2010.asp?metodo $=1 \&$ tano $=2010 \&$ tUF $=$ RIO+GRANDE+DO+SULCEMUNICIPIO= santa+maria\&tSubmit=Consultar>. Acesso em: 10 jan. 2011.

INEP. Dados de Santa Rosa. Educacenso, Brasilia, DF, 2010b. Disponível em: $<$ http://www.educasensomec.inep.gov.br/basica/censo/Escolar/Matricula/ censoescolar_2010.asp?metodo=1\&tano=2010\&UF=RIO+GRANDE+DO+SULCtMUNICIPIO $=$ santa + RoSaftSubmit $=$ Consultar $>$. Acesso em: 10 jan. 2011.

SANTA MARIA (RS). Prefeitura. Lei no 3.956, de 15 de janeiro de 1996. Dispõe sobre o conselho municipal de educação e dá outras providências. Santa Maria, 1996. Disponivel em: <www.jusbrasil.com.br/legislacao/540703/lei-3956-96santa-maria-rs>. Acesso em: 10 ago. 2011.

. Prefeitura. Lei no 4.122, de 22 de dezembro de 1997. Dispõe sobre o Conselho Municipal de Educação e dá outras providências, 1997. Santa Maria, 1997a.

. Prefeitura. Lei no 4.123, de 22 de dezembro de 1997. Cria o Sistema Municipal de Ensino de Santa Maria. Santa Maria, $1997 b$.

SANTA MARIA (RS). Prefeitura. Lei no. 5.023, de 27 de julho de 2007. Autoriza o Poder Executivo Municipal a criar o Programa de Prevenção e Controle do Diabetes em Crianças e Adolescentes Matriculados nas Escolas da Rede Pública Municipal de Ensino. Santa Maria, 2007. Disponível em: <http://www.camara-sm.rs.gov.br/2010/ arquivos/legislacao/LM/2007/5023.pdf>. Acesso em: 10 ago. 2011. 
SANTA MARIA (RS). Regimento Interno do Conselho Municipal de Educação de

Santa Maria: aprovado em 11 de dezembro de 1998. Santa Maria, 1998.

SANTA ROSA (RS). Conselho Municipal de Educação. Lei no 4.530, de 20 de maio de 2009. Consolida a legislação municipal da educação. Santa Rosa, 2009a.

Prefeitura. Lei no 3.211, de 14 de julho de 1999. Criação do Sistema Municipal de Ensino. Santa Rosa, 1999a.

Prefeitura. Lei no 3.212, de 14 de julho de 1999. Criação do Conselho Municipal de Educação. Santa Rosa, 19996.

Prefeitura. Lei $n^{\circ} 4.477$, de 5 de janeiro de 2009. Dispõe sobre a estrutura administrativa da Prefeitura Municipal de Santa Rosa. Santa Rosa, $2009 \mathrm{~b}$.

- Regimento Interno do Conselho Municipal de Educação de Santa Rosa/ RS. Santa Rosa, 2003. Mimeografado.

SOUZA, D. B.; FARIA, L. C. M. Reforma do Estado, descentralização e municipalização do ensino no Brasil: a gestão política dos sistemas públicos do ensino pós-LDB 9.394/96. Ensaio: avaliação e políticas públicas em educação. Rio de Janeiro, v. 12, n. 45, p. 925-944, out./dez. 2004.

SOUZA, D. B.; VASCONCELOS, M. C. C. Os Conselhos Municipais de Educação no Brasil: um balanço das referências nacionais (1996-2002). Ensaio: avaliação e políticas públicas em educação, Rio de Janeiro, v.14, n. 50, p. 39-51, jan./mar. 2006.

TEIXEIRA, L. H. Conselhos Municipais de Educação: autonomia e democratização do ensino. Cadernos de Pesquisa, São Paulo, v. 34, n. 123, p. 691-708, set./dez. 2004.

TELES, R. M. 0 papel dos Conselhos de Educação na formação dos sistemas educacionais brasileiros. In: REUNIÃO ANUAL DA ANPED, 24., 2001, Caxambu. Trabalhos apresentados... Caxambu: ANPED, 2001. Disponivel em: <www.anped.org.br/reunioes/24/P0522902106281.DOC>. Acesso em: 17 ago. 2010.

WERLE, F. O. C. Gestão da educação municipal: composição dos Conselhos Municipais de Educação do Rio Grande do Sul. Ensaio: avaliação e políticas públicas em educação. Rio de Janeiro, v. 14, n. 52, p. 349-364, jul./set. 2006.

Recebido em: 14/03/2011

Aceito para publicação em: 23/5/2011 